\title{
IS FRAILTY AND NOT CHRONOLOGICAL AGE THE ESSENTIAL PROGNOSTIC ELEMENT IN OLDER PATIENTS WITH COVID-19?
}

\section{Será a fragilidade e não a idade cronológica o elemento prognóstico essencial no paciente idoso com COVID-19?}

Clinically, the pandemia for coronavirus disease (COVID-19) can present with a plethora of signs and symptoms, ranging from mild cases, treated at home, to acute respiratory distress syndrome, requiring hospitalization in intensive care units. $\mathrm{Wu}$ and McGoogan (2020) reported that most infected people have mild symptoms (81\%), and only a fraction of those infected develop severe disease (18.1\%) and die (3.5\%). ${ }^{1}$ Individuals with advanced age or comorbidities - arterial hypertension, diabetes mellitus, cardiovascular disease, and chronic obstructive pulmonary disease (COPD) - are those with the worst outcomes (hospitalization in intensive care units, mechanical ventilation, and death). ${ }^{2}$

Among all the challenges posed by the current pandemic, it is important to highlight the potential difficulty in diagnosis in older individuals, which is a critical aspect given that they are a well-known risk group for adverse outcomes. It is worth noting that a significant proportion of the older population has acute diseases with atypical manifestations. Fever, for example, which is the most prevalent and flagging symptom of COVID- $19,{ }^{3}$ is uncommon in infections that affect older individuals, especially the most frail. On the other hand, delirium may be the only presentation of an ongoing disease. Cough and tiredness, however, are persistent complaints among older patients, due to conditions such as heart failure, chronic obstructive pulmonary disease, and bacterial pneumonia, among others. ${ }^{4}$ These peculiarities have a tremendous negative impact on the accuracy of the diagnostic suspicion, leading to a delay in the detection of COVID-19 or an unnecessary expenditure of financial, human, and social resources. Perhaps the low accuracy of the syndromic diagnosis of the new coronavirus in older individuals may play a role in the high fatality rate in this age group.

As we prepare for the imminent impact of the coronavirus pandemic, considerable controversy has been generated about how to best minimize the risk of fatal diseases among the most vulnerable. If epidemiological data have shown an unequal impact on the population, with an exponential increase in the severity and mortality of the disease in those who are over 60 years of age, ${ }^{5}$ chronological age alone, nevertheless, does not seem to be the most critical risk factor for these outcomes. ${ }^{6}$

Understanding the multidimensional aspects of health in older people infected with SARS-CoV-2, and not just in severe cases, is crucial for identifying the subgroup at highest risk. Although the prognosis of patients with COVID-19 is negatively affected by multimorbidity, this information is not sufficient. As in other conditions, functioning and cognition are probably the key elements in determining prognosis in older patients. ${ }^{7}$ In the care of older people, it is essential to identify those who are frail, ${ }^{7}$ understanding that frailty represents a state of age-related physiological vulnerability caused by decreased homeostatic reserve and a reduced ability of the body to face a number of adverse health outcomes, such as hospitalization, falls, and functional loss, with an increased probability of death. ${ }^{8}$

One of the principles of care in older persons is to identify which individuals will benefit from multidisciplinary interventions that are personalized and oriented toward specific goals, such as identifying patients at risk of adverse health outcomes and death. Despite the specificity of the current risk condition, the disease caused by SARS-CoV-2 is one of the challenges that the scientific community that specializes in human aging has to face, understanding that it is not enough to know the age of an individual. Indeed, functional status is usually a much more accurate predictor of adverse health outcomes than age or comorbidities. Frailty, when properly assessed and based on how the person has behaved for at least 2 weeks before the onset of the disease, is an essential measure that can guide goal setting. The degree 
of frailty is vital to determine how an individual's needs can be met. ${ }^{9,10}$

It is important to note that frailty assessment can help ensure that health care decisions are not based solely on the person's age, but that they are individualized and based on a holistic assessment. This approach is particularly relevant in the current COVID-19 pandemic, when nosological experience and disease history can follow very distinct courses among different individuals.

\author{
Roberto Alves Lourenço \\ Editor-in-chief
}

Mariangela Perez

Geriatric, Geriatric Unit Prof. Mario A. Sayeg,

Piquet Carneiro Polyclinic, Universidade do

Estado do Rio de Janeiro

\section{REFERENCES}

1. Wu Z, McGoogan JM. Characteristics of and Important Lessons From the Coronavirus Disease 2019 (COVID-19) Outbreak in China: Summary of a Report of 72314 Cases From the Chinese Center for Disease Control and Prevention. JAMA. 2020. https://doi.org/10.1001/jama.2020.2648

2. Guo YR, Cao QD, Hong ZS, Tan YY, Chen SD, Jin HJ, et al. The origin, transmission and clinical therapies on coronavirus disease 2019 (COVID19) outbreak - an update on the status. Mil Med Res. 2020;7(1):11. https://doi.org/10.1186/s40779-020-00240-0

3. Gandhi RT, Lynch JB, Rio C. Mild or Moderate Covid-19. New Engl J Med. 2020. [Accessed in June 15, 2020]. Available at: https://doi. org/10.1056/nejmcp2009249

4. Nikolich-Zugich J, Knox KS, Rios CT, Natt B, Bhattacharya D, Fain MJ. SARS-CoV-2 and COVID-19 in older adults: what we may expect regarding pathogenesis, immune responses, and outcomes. Geroscience. 2020;42(2):505-14. https://dx.doi.org/10.1007\%2Fs11357-020-00186-0

5. AlGhatrif M, Cingolani O, Lakatta EG. The Dilemma of Coronavirus Disease 2019, Aging, and Cardiovascular Disease: Insights From Cardiovascular Aging Science. JAMA Cardiol. 2020. https://doi. org/10.1001/jamacardio.2020.1329
6. Wang L, He W Yu X Hu D, Bao M, Liu H et al Coronavirus Disease 2019 in elderly patients: characteristics and prognostic factors based on 4-week follow-up. J Infect. 2020;80(6):639-45. https://doi. org/10.1016/j.jinf.2020.03.019

7. Polidori MC, Maggi S, Mattace-Raso F, Pilotto A. The unavoidable costs of frailty: a geriatric perspective in the time of COVID-19. Geriatric Care. 2020;6(1). https://doi.org/10.4081/gc.2020.8989

8. Lourenço RA, Moreira VIG, Mello RGB, Santos IS, Lin SM, Pinto ALF, et al. Brazilian consensus on frailty in older people: concepts, epidemiology and evaluation instruments. Geriatr Gerontol Aging. 2018;12(2):12135. https://doi.org/10.5327/Z2447-211520181800023

9. National Institute for Health and Care Excellence. COVID-19 rapid guideline: critical care in adults [Internet]. National Institute for Health and Care Excellence; 2020 [Accessed in June 15, 2020]. Available at: www.nice.org.uk/guidance/ng159

10. Conroy S. Frailty - busting a few myths about what it is and what it isn't [Internet]. Britsh Geriatrics Society; 2020 [Accessed in June 15, 2020]. Available at: https://www.bgs.org.uk/blog/frailty---busting-afew-myths-about-what-it-is-and-what-it-isn't 